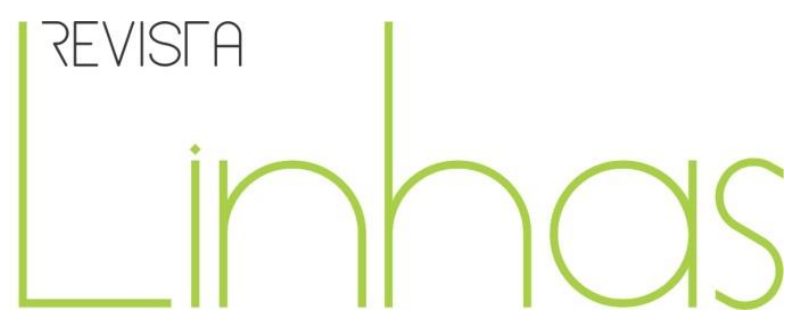

\title{
Práticas de leitura e escritas em rede: modos de ser e estar no mundo
}

\begin{abstract}
Resumo
Leitores do livro impresso realizaram "práticas de leitura intensiva e extensiva” (Chartier, 2002), escreveram memórias dessas leituras, criaram seus próprios textos e constituíram uma rede de interatividade traduzida por compartilhamentos na internet, no período de publicação de 2009 a 2014. Tomando por base essa constatação, o objetivo central deste estudo refere-se às práticas de leitura reveladas a partir da fonte principal: as escritas de textos em suportes eletrônicos de sete leitores das obras de Erico Verissimo oriundos de diferentes regiões do Brasil, e integrantes de "redes" específicas de comunicação e socialização. Os princípios teóricometodológicos adotados articulam as áreas de História da Educação e História do Livro e da Leitura, com ênfase nas análises de Michel de Certeau (1994) sobre as relações entre as "operações" envolvidas no ato de ler e os aspectos culturais nele imbricados. Os leitores em foco compartilharam experiências e narraram percursos singulares de conhecimento da literatura dentro e fora da escola ao relatarem como conheceram o escritor, identificaram as obras e as suas personagens favoritas. $O$ sentimento de pertencimento a um grupo indica haver uma mútua cooperação a partir das ações dos leitores em sugerir propostas coletivas, dialogar, tomar decisões, comentar nos fóruns, e-mails e mensagens. Por essa razão, a partir do momento em que se identificam como um "grupo de admiradores" de Erico Verissimo, os participantes desta comunidade constroem modos de ser e estar no mundo, e assim, transmitem suas convicções e perspectivas por intermédio dos seus percursos educacionais.
\end{abstract}

Palavras-chave: Práticas de Leitura. Leitor. Leitura. Escrita.

\section{Roselusia Teresa de Morais Oliveira}

Universidade Federal de Sergipe

- UFS - Aracaju/SE - Brasil

roselusiamorais@gmail.com

\section{Para citar este artigo:}

OLIVEIRA, Roselusia Teresa de Morais. Práticas de leitura e escritas em rede: modos de ser e estar no mundo. Revista Linhas. Florianópolis, v. 19, n. 41, p. 94-116, set./dez. 2018. 


\title{
Reading and writing in the network: ways of being and being in the world
}

\begin{abstract}
Readers of the printed book carried out "intensive and extensive reading practices" (Chartier, 2002), wrote memoirs of these readings, created their own texts, and formed a network of interactivity by Internet Shares in the publication period from 2009 to 2014 . Based on this observation, the main objective of this study is the reading practices revealed from the main source: the writing of texts placed on electronic means of seven readers of the works of Erico Verissimo which came from different regions of Brazil, and members of specific "networks" of communication and socialization. The theoretical-methodological principles adopted, articulate the areas of History of Education and History of Book and Reading, with emphasis on the analysis of Michel de Certeau (1994) on the relations between the "operations" involved in reading and the cultural aspects in him imbricated. Focusing readers shared experiences and narrated unique literary pathways in and out of school to report how they met the writer, identified the works and their favorite characters. The feeling of belonging to a group indicates a mutual cooperation based on the actions of the readers in suggesting collective proposals, dialoguing, making decisions, commenting on forums, emails and messages. For this reason, once they identify themselves as a "group of admirers" of Erico Verissimo, the participants of this community construct ways of being and being in the world, and thus transmit their convictions and perspectives through their educational pathways.
\end{abstract}

Keywords: Reading Practices. Reader. Reading. Writing. 


\section{Uma comunidade de leitores de Erico Verissimo: apontamentos iniciais}

A leitura não é somente uma operação abstrata de intelecção: é por em jogo o corpo, é inscrição num espaço, relação consigo ou com o outro. Por isso devem ser reconstruídas as maneiras de ler próprias a cada comunidade de leitores, a cada uma dessas 'interpretative communities' de que fala Stanley Fish. (CHARTIER, 2002a, p. 70)

Este estudo revela uma comunidade de leitores de Erico Verissimo ${ }^{1}$ com práticas de leitura feitas em espaços privados e públicos. Leitores do livro impresso realizaram "práticas de leitura intensiva e extensiva” (CHARTIER, 2002a), escreveram memórias dessas leituras, criaram seus próprios textos e constituíram uma rede de interatividade traduzida por compartilhamentos na internet. Oriundos de diferentes regiões do Brasil, estabeleceram redes com a finalidade de escrever acerca das suas experiências de leituras, no período de publicação de 2009 a $2014^{2}$. Tomando por base essa constatação, o objetivo central deste artigo refere-se às práticas de leitura, reveladas a partir da fonte principal: as escritas de textos em suportes eletrônicos de sete leitores das obras de Erico Verissimo, e integrantes de "redes" específicas de comunicação e socialização.

Os princípios teórico-metodológicos adotados articulam, principalmente, as seguintes áreas de interesse: História da Educação; e História do Livro e da Leitura, com ênfase nas análises de Michel de Certeau (1994) sobre as relações entre as "operações” envolvidas no ato de ler e os aspectos culturais nele imbricados. Fundamentada em Chartier (2002), as leituras são "intensa” e "intensiva”, uma vez que a percepção do leitor é comprometida e habita o cotidiano daqueles que se sentem envolvidos na leitura.

O referencial no campo da História do Livro aponta um "circuito de comunicação" (DARNTON, 1995, p. 112) incluindo assim as seguintes esferas: produção, edição,

\footnotetext{
${ }^{1} \mathrm{O}$ nome de Erico Verissimo não é acentuado (VERISSIMO, 1981). Por essa razão, optei por não acentuar o nome de escritor, com a finalidade de preservar a forma original da certidão de nascimento.

${ }^{2}$ Este trabalho é parte integrante da Tese de Doutorado concluída e intitulada: "Modos de ler o impresso, modos de escrever na internet: escritas de leitores e leitoras do escritor Erico Verissimo" (MORAIS, 2014), desenvolvida sob a orientação da professora Dra. Eliane Peres, do curso de Pós-Graduação em Educação, da Universidade Federal de Pelotas. Esta pesquisa contou com o financiamento da CAPES (Coordenação de Aperfeiçoamento de Pessoal de Nível Superior). O estudo também apresenta os resultados da experiência realizada por meio do Doutorado Sanduíche na Université de Cergy-Pontoise, na França, por meio do Programa Institucional de Bolsas de Doutorado Sanduíche no Exterior (PDSE-CAPES/ Governo Federal Brasileiro), sob a coorientação do professor Dr. Max Butlen.
} 
distribuição, circulação e, por fim, o leitor. Esse "circuito" admite que há variações das condições conforme o lugar e a época, mas de modo geral pode ser descrito em um modelo que considera o percurso desde o autor, o editor, o impressor, o distribuidor, o vendedor até chegar nas mãos do leitor. Neste trabalho, é analisado um aspecto desse "circuito" que é a instância do leitor, considerado como o "estágio" de difícil acesso de estudos (DARNTON, 1995).

Revelados nos dados de pesquisa coletados, as escritas de leitores e leitoras na internet são indicadores que definem "modos de leitura". Para a análise desses dados, cabe referenciar conceitos do campo da Cibercultura, a exemplo de "rede" e “cibercultura”, do autor Pierre Lévy $(1995 ; 2007)$ e entre outros autores como Manuel Castells (2005) e Hugo Assmann (2005).

Em tempos de internet, leitor@s3 de Erico Verissimo publicaram sobre as suas experiências de leituras em blogs, criaram sites, participaram de comunidades e grupos de discussões. Baseado nessa constatação, esta investigação propõe uma discussão teórica sobre a produção de um grupo de leitores e leitoras em redes sociais, na internet, como uma possibilidade de fonte para a História da Leitura e do Livro. Nesse sentido, o foco de análise é identificar os modos de ler o livro impresso por meio dos modos de escrever textos eletrônicos em ambientes selecionados na internet a partir das interações promovidas nesse espaço, no período de publicação de 2009 a 2014.

Eles compõem um grupo heterogêneo de seis pessoas do sexo feminino e uma do sexo masculino, com faixa etária distinta e carreira profissional também diversa. Eles leem obras impressas de Erico Verissimo pelo prazer, pela fruição e pelas emoções que essas leituras lhes provocam. As suas escritas virtuais indicam que a leitura "não é somente uma operação abstrata de intelecção" (CHARTIER, 2002a, p. 70), mas acontece e é revelada também a partir da inscrição do próprio corpo no espaço, dos gestos e da escolha do suporte (impresso).

As escritas virtuais analisadas possibilitaram mapear e compreender, portanto, quem são alguns dos leitores de Erico Verissimo, como conheceram o escritor, quais são seus personagens e livros favoritos, com que intensidade leem, como leem e o que

\footnotetext{
3 O termo adotado "leitor@s" compreende os leitores e as leitoras, analisados/analisadas ao longo da pesquisa realizada e que transitam no espaço da internet.
} 
sentem quando leem. Os dados capturados na internet foram delimitados e analisados como memórias desses leitores que evidenciam, entre outas coisas, a paixão pelo escritor, a materialidade dos livros, o gosto e a preferência pela leitura no impresso, os gestos no momento da leitura, e a relação deles com as obras.

\section{Conectados em redes: leitores participantes-visualizadores e escritores em tela}

Os modos de ler e o processo pelo qual os leitores dão sentidos aos textos dos quais se apropriam, refere-se à perspectiva discutida por Chartier (2002a) como a possibilidade de pensar a "produção da significação", o que implica uma relação dialógica entre as propostas das obras e as categorias estéticas e interpretativas de seus públicos leitores. Nesta perspectiva, significa refletir a interação dinâmica entre o texto e o leitor, as práticas ordinárias e as experiências de vida dos leitores.

Outro aspecto que pode ser aqui considerado é que a literatura (e a leitura literária) pode ser analisada sob várias dimensões, desde as leituras escolares até a sua prática não obrigatória ou não profissional. Segundo Mathieu Bégin (2011), raro é localizar pesquisas que se dediquem à literatura como uma prática de divertimento, de socialização e de enriquecimento pessoal. Este trabalho identifica justamente tais dimensões raras em termos de pesquisa e analisa pelo viés da história das práticas de leitura como esse território - da leitura por prazer - é revelado pelos leitores de rico Verissimo $(E V)^{4}$.

Max Butlen (2008) afirma que o crescimento das práticas de leitura diante da disponibilidade das informações acessíveis por vários meios eletrônicos tem provocado a redefinição da leitura e dos leitores. Na virada do século XX para o XXI, o relevante aumento das práticas de leitura caracteriza um período em que muitas obras estão sendo disponibilizadas por meio digital. Essa discussão gira em torno da promoção e apropriação da leitura, ou seja, da ampliação da oferta dos livros, da recepção dos textos por parte dos leitores e, de alguma forma, também da produção escrita de leitores nas redes sociais.

\footnotetext{
${ }^{4}$ EV: abreviação criada para fazer referência ao nome do escritor Erico Verissimo.
} 
Nessa direção, o sujeito leitor focalizado neste trabalho, ou seja, o leitor de Erico Verissimo e suas práticas de leitura, revela motivos para ler este autor em específico, qual importância têm os livros especialmente de EV em suas vidas, quais sentidos e relações estabelecem nesta e a partir da leitura dessas obras. Isso foi possível apreender porque as competências dos LEV 5 os caracterizam como leitores que também são "escritores" capazes de discutir assuntos na internet relacionados às obras lidas, de ler seletivamente e analisar o conteúdo lido, de fazer relações intertextuais e extratextuais, de relacionar vários conhecimentos a partir das leituras feitas.

Os leitores de Erico Verissimo (LEV) na internet se "apoderaram" dos livros e constituíram uma "comunidade de leitores" (CAVALLO; CHARTIER, 1997, p. 38), que compartilharam variadas leituras, habilidades, códigos, hábitos e práticas por meio das escritas virtuais. Os sujeitos formaram um grupo de pessoas com gostos de leitura em comum e até gestos e maneiras de ler que se aproximaram dos seus "esquemas de percepção" e “julgamentos”. Contudo, cada leitor é singular ao atribuir sentidos diversos ao que leem e produzem criativamente sua própria escrita para socializar nas redes virtuais. Assim, a comunidade dos sete leitores de Erico Verissimo que publicaram na internet constitui um grupo com características diversas e vivências singulares que compartilharam interpretações e práticas de leitura.

Neste âmbito, à luz do pensamento de Chartier (1999, p. 216), é possível definir uma comunidade de leitores como "aquelas comunidades interpretativas, cujos membros compartilharam os mesmos estilos de leitura e as mesmas estratégias de interpretação". Essas "comunidades de leitores" sinalizam, a partir de suas práticas, "como os mesmos textos podem ser diversamente apreendidos, manejados e compreendidos por indivíduos diferentes" (CHARTIER, 1999, p. 11). Os integrantes das comunidades interpretativas analisadas compartilham os estilos de leitura e estratégias de interpretação, por meio das escritas na internet, tendo, contudo, apreensões diversas das leituras realizadas. Como mencionado, sete leitores, de um conjunto de tantos outros na internet, responderam às questões de pesquisa nas redes analisadas, ao comporem uma "comunidade de leitores".

Trata-se de um grupo com integrantes de várias partes do Brasil, reunindo moradores das regiões Nordeste, Sudeste e do Sul do país. Eles têm diferentes idades,

\footnotetext{
${ }^{5}$ LEV: abreviação criada para fazer referência aos leitores e leitoras do escritor Erico Verissimo.
} 
entre 20 a 59 anos, e igualmente profissões de diversas áreas. Em relação ao nível de escolaridade, um dado significativo é a predominância do nível superior, em andamento ou concluído. As especialidades profissionais dos LEV são: edificações, administração de negócios em meio rural, advocacia, autoria e publicação de livros impressos e digitais e, são também, estudantes da educação superior, no nível de graduação, das áreas de Psicologia, Pedagogia e Arqueologia. Desse modo, percebe-se que o viés profissional também não é o elemento comum entre eles.

O estado civil dos mesmos também é diversificado: quatro (4) são solteiros, duas (2) casadas e uma (1) divorciada. É relevante considerar a questão de gênero: há seis (6) mulheres e um (1) homem no grupo, sendo que não havia critério outro para participar do grupo (escolaridade, cidade, formação, profissão), exceto a experiência de leitura e o gosto pelas obras de Erico Verssimo.

Esse grupo tinha em comum o interesse pela obra de EV e o diálogo nas redes. Cabe destacar que a seleção de um grupo de leitores moradores de regiões distintas do Brasil, com faixa etária diversa e diferentes profissões não foi intencional. Não havia critérios previamente definidos, mas, ao contrário, os leitores foram escolhidos pela disponibilidade em participar da pesquisa e da própria atuação significativa destes nas redes virtuais mencionadas.

Ainda, considerando a idade, os LEV correspondem a duas distintas categorias, com base nos indicadores do Instituto Brasileiro de Geografia e Estatística - IBGE (2010): o segmento social jovem, correspondente ao grupo de 15 a 24 anos de idade; e o dos adultos, relativo ao grupo de 25 aos 59 anos de idade. Então, o grupo selecionado para a investigação compreende de jovens e adultos, homens e mulheres.

Em relação aos sete leitores de EV, é possível ainda considerar que não são as “institutions de transmission" (OCTOBRE, 2010, p. 4) que os caracterizam, ou seja, não são as instituições de transmissão as principais responsáveis pela prática e gosto da leitura de EV (neste caso, a escola, por exemplo), mas as práticas de entretenimento, de compartilhamentos e atividades de criação e reinvenção do ato de ler e escrever. Se, por um lado, no início do século XXI, conforme Octobre (2010), a geração dos jovens de 15 a 25 anos nasceu em um mundo marcado por tecnologias de informação e comunicação com seus objetos midiáticos e seus usos, que lhes permitem novas formas de exibição, 
novas mensagens e ferramentas de criação, por outro lado, nesta investigação, foi constatado que os "nativos digitais", os jovens "fascinados" pelas novas tecnologias, interagem e convivem, virtualmente, com outras faixas etárias.

No caso da atuação no espaço virtual, os leitores de EV foram criadores de blogs; atuantes no Orkut $^{6}$ e criadores de Fanpage ${ }^{7}$. As características principais identificadas durante a coleta de dados da pesquisa foram: a manifestação das ideias, a postagem e o ato de personalizar as mensagens a partir do uso de diferentes fontes de letras, cores e imagens por parte de cada LEV, a viabilidade de criar pastas ou fóruns tanto no grupo de discussão Google, como no Orkut e Facebook, a reunião das discussões em um espaço (o virtual), a sua própria edição dos textos e a utilização de fotos e apelidos. Um dos primeiros "achados" da pesquisa foi, então, o blog em homenagem ao escritor gaúcho ${ }^{8}$.

Cada leitor estudado tem, assim, uma especificidade de atuação virtual, isso porque nem todos são criadores de blog, nem todos têm a mesma participação efetiva nas redes, mas eles se constituem como uma espécie de colaboradores uns dos outros, formando, de alguma forma, um coletivo, na medida em que surge um "espírito" de solidariedade e partilham especialmente acerca do que o outro produz e publica.

Os dados demonstram que esses leitores de EV transitaram entre dois espaços de leitura: o impresso e o digital. Foi ressaltada por unanimidade a preferência dos LEV pelo suporte impresso. Nenhum deles afirmou ler as obras de EV on-line, embora leiam também na internet. Eles afirmaram ler no modo impresso as obras de EV e referenciaram a internet como espaço para outras leituras que não são as literárias, mas sim de caráter efêmero, superficial ou de informação.

Os LEV enfatizaram uma posição diferenciada entre o texto lido na tela e no papel. Este dado pode ser compreendido a partir de Regis (2005), quando problematiza o ciberespaço como um "não-lugar”, ou seja, destaca uma rede de dados navegáveis em um

\footnotetext{
${ }^{6}$ O Orkut foi uma rede social filiada ao Google, criada em 2004 e desativada em setembro de 2014. O criador, projetista chefe, foi Orkut Büyükkökten, engenheiro turco do Google.

${ }^{7}$ Fanpage ou página de fãs é uma página específica do Facebook destinada para empresas ou marcas. Neste caso da pesquisa, atende iniciativas individuais para divulgação da obra de Erico Verissimo.

${ }^{8}$ No momento em que foi localizado o referido blog, havia a indicação de outro blog intitulado: Gato Branco em fuligem de carvão, e um grupo de discussão de leitores de EV. Foi o princípio de uma trama investigativa para constituir a formação das redes de leitores que escreviam na internet as suas impressões sobre a leitura das obras do escritor gaúcho, foco primeiro do estudo. Potencialmente, a primeira etapa direcionou outras fontes de pesquisa, para ter acesso aos LEV.
} 
espaço imaterial, ou “espaço incorpóreo”. Nesse caso, a tela eletrônica é um suporte de leitura e escrita dos LEV para finalidades a que eles atribuíram com um significado transitório, efêmero, superficial. Por outro lado, o texto impresso tem uma materialidade concreta e objetiva, como visto nos relatos dos pesquisados.

Como eles participaram de redes específicas, demonstraram uma forte vinculação com o modo de ler o impresso e isso se expressou no modo de escrita na internet. Por essa razão, a definição das modalidades de participação nas redes pesquisadas contribuiu para constituir dois tipos de leitores, a partir do universo amplo de leitores de Erico Verissimo na internet, ou seja, foram capturadas duas formas de participação.

Identificou-se, a partir da observação dos grupos, que nas redes havia perfis de usuários diferenciados, isso porque se manifestavam distintamente e tal reconhecimento se constituiu em uma decisiva caracterização dos participantes da pesquisa. Por isso, foram criados os conceitos: "LEV escritores" e "LEV participantes-visualizadores", para demarcar, inicialmente, uma diferença de caráter qualitativa que pode ser visualizada na Figura 1:

Figura 1 - Modalidades de participação dos Leitores de Erico Verissimo nas redes investigadas

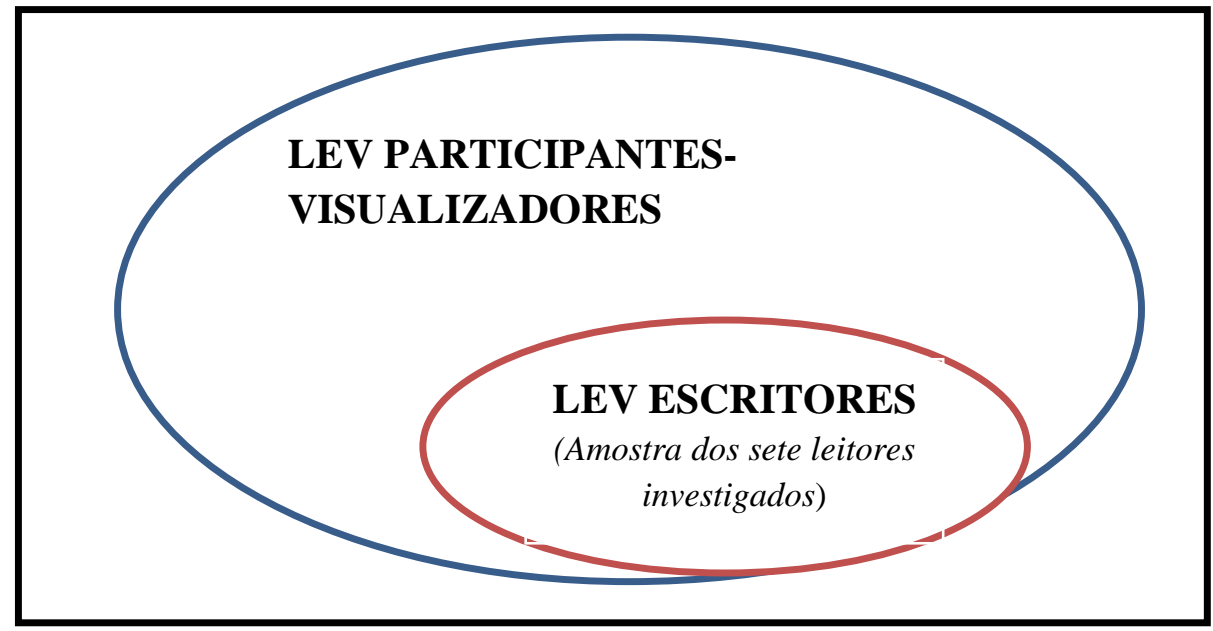

Fonte: MORAIS, 2014.

A observação dos dados constatou que nem todos escreveram e participaram do mesmo modo. Em síntese, há aqueles que escreveram recorrentemente, neste caso, são os LEV escritores, e há aqueles que fazem parte da rede, mas não escreveram, são, 
portanto, os participantes-visualizadores. Os sete LEV deste estudo foram classificados como LEV participantes-visualizadores e escritores, uma vez que integraram um grupo que compartilha e interage virtualmente por meio da troca de escritas, imagens, vídeos, etc. A modalidade de participação deles nas redes investigadas foram as pistas necessárias para localizar os modos de ler, ou seja, escolheu-se um grupo de sete leitores de uma comunidade leitora e que indicaram suas práticas por meio de memórias escritas.

Esta definição de modalidade de participação contou com o cruzamento das informações disponíveis do perfil de cada rede pesquisada e a quantidade de integrantes a partir do princípio de participação efetiva deles por meio das escritas. Foi identificado um número maior de LEV que participaram e/ ou visualizaram exclusivamente, se comparado em relação ao grupo de LEV escritores, isso tanto no grupo de discussão no Gmail $^{9}$, como na página do blog, na comunidade do Orkut, ou, ainda, no grupo de discussão no Facebook. ${ }^{10}$

Os LEV participantes-visualizadores, definidos neste estudo, compõem quantitativamente um grupo de interesse que tem o mesmo gosto literário, participa da mesma rede ou de um conjunto de redes. Ao solicitarem virtualmente a participação nas redes, eles fazem parte de uma "cultura digital” (AURAY, 2010), ou seja, de novas formas de promoção e circulação das informações em um espaço em que as fronteiras entre a leitura e escrita são tênues. Eles não expressaram a sua visibilidade pelos comentários publicados, mas atuaram como expectadores que fazem parte de um coletivo dinâmico, aberto e intenso.

Em tempos de internet, reflexões sobre as escolhas de livros para ler, sejam eles impressos ou não, promovem novos espaços eletrônicos que delineiam a formação de novos lugares de comunicação e de invenção criativa entre os usuários. Um conjunto de pesquisadores franceses, como Octobre, Auray, Regis e Severac, na Revista Lecture Jeune 11 (2010), nomeiam por “culture numérique”, ou seja, cultura digital, as práticas

\footnotetext{
${ }^{9}$ Gmail é um serviço gratuito de webmail criado pela Google em 2004.

${ }^{10}$ Os dados quantitativos da pesquisa realizada podem ser consultados em: MORAIS, 2014.

${ }^{11}$ Revista trimestral francesa. Em 2010, completava o $33^{\circ}$ ano de edição. Revista editada pela l'Association Lecture Jeunesse, da lei 1901, declarada em 4 de janeiro de 1974. A Associação de Leitura Juvenil é composta de uma equipe permanente de profissionais que utiliza a contribuição de voluntários que trazem sua experiência e apoio ao trabalho da associação. É composta por profissionais de mediação e leitura, como por exemplo: bibliotecários, arquivistas, professores, assistentes sociais, etc. Além da publicação da revista,
} 
culturais nos meios eletrônicos a partir das intensas modificações das condições de acesso à cultura de um público, verificadas nos últimos anos. Eles analisam os progressos dos equipamentos eletrônicos e multimídia, a generalização da internet banda larga, a pluralidade de conteúdos conjugados em um mesmo suporte material ao observarem novas redes de sociabilidade expressas em blogs, jogos e outras redes sociais, com quem os próprios usuários convivem e fazem parte de tais mudanças tecnológicas que geram condições de acesso à cultura.

Fundamentalmente, os LEV escritores, portanto, os sujeitos desta pesquisa, também fazem parte do grupo dos participantes-visualizadores, uma vez que do mesmo modo, desempenharam o papel de participar do grupo e visualizar as mensagens, mas, além desse perfil, eles produziam recorrentemente escritas próprias ou divulgação de informações relacionadas à literatura de EV.

Cada um dos leitores produziu uma imagem de si que pode ser revelada em nuances ou facetas a partir das suas escritas na internet. Esse contato revelou modalidades de participação na internet como um suporte de escrita que os mantêm conectados ao mundo social. Tais registros podem ser redigidos, reescritos ou até mesmo apagados, conforme as decisões que os leitores desejam expressar e, assim, proporcionam visibilidade sobre modos de pensar e de se relacionar no mundo.

Os registros diferenciados, na internet, com múltiplas faces do indivíduo o definem por "identité numérique" (AGUITON; CARDON, 2010). São formatos de visibilidade que caracterizam a escolha da sua aparência visual na rede, assim, expõe o sexo, a idade, o estado civil, os traços de personalidade, a rede social, a inserção em determinados grupos com temáticas de interesse; além disso, falam sobre o cotidiano, expressam suas paixões, gostos, interesses. Esses elementos determinam o indivíduo no virtual e este, por sua vez, não precisa, necessariamente, estar vinculado às suas características reais.

Os LEV foram atraídos pela leitura do escritor por iniciativa própria e se identificam com a natureza literária de EV, ou seja, eles não vincularam as suas leituras às atividades

\footnotetext{
a associação também promove Colóquios com o apoio do Ministério da Cultura e da Comunicação da França. As principais áreas de atividade da Association Lecture Jeunesse são: a organização e formação de grupos em Paris e em sites na França e no exterior; a proposta de jornadas de estudo; a publicação da revista Lecture Jeune; a organização de Comitês "jeunes critiques", jovens críticos; a provisão de recursos e a coordenação de uma rede para a troca e partilha de práticas profissionais em direção aos adolescentes. Maiores informações por meio do site: <www.lecturejeunesse.com>.
} 
escolares ou profissionais. No ato de ler, eles processam os conhecimentos pela interposição de ações que geram percepção, atenção, raciocínio, julgamento, memória, imaginação, pensamento sobre o que leem.

Os sete LEV escritores prontamente respondiam às perguntas da pesquisa, e esse mesmo grupo promovia a socialização literária publicando trechos das obras, comentários sobre as obras, indicações de leitura, escreviam críticas sobre o que era lido e expectativas de futuras leituras; compartilhavam suas emoções como leitores sensíveis, destacando o prazer da leitura e o encantamento por obras de EV.

A interatividade dos participantes confirma alguns discursos sobre a leitura tratados por Chartier, A.M. e Hébrard (2000), quando afirmam a constituição de um novo modelo de "lecture libre et plurielle", ou seja, a "leitura livre e plural" a partir de uma perspectiva sócio-histórica sobre os discursos realizados na França acerca das práticas de leitura $^{12}$. A análise envolve os fundamentos da cultura que interferem na formação de leitores e, desse modo, as diferentes formas de ler, distintas aprendizagens e o ensino da leitura. Nesta direção, as mudanças da relação entre leitor e livro, ao longo da história, a partir de instâncias sociais que promovem e fortalecem o surgimento de um novo modelo de leitura que se aproxima da ideia de que o leitor lê livremente e de maneira múltipla. Esse novo modelo de leitura é evidenciado neste estudo, ao apontar o fato de que os LEV são incentivados a serem livres e autônomos utilizando a ferramenta digital, portanto, eles definem suas práticas de leitura e escrita e a partir das relações sociais "inventam" modos virtuais de partilhar o que leram.

As escritas virtuais dos LEV permitem também expressar suas individualidades a partir da difusão de arquivos pessoais, com fotografias, narrativas e vídeos. Apesar de reconhecer nos dados coletados essas práticas de escrita na rede, como ações criativas, elas também se caracterizam em duplo formato: a) quando as escritas são de autoria dos LEV; e b) quando eles transcrevem trechos da internet ou, ainda, copiam dos próprios livros impressos, ou seja, do seu acervo particular. Então, é necessário situar e observar a dimensão do leitor criador, que neste âmbito está diretamente ligada a alguém capaz de divulgar suas produções inéditas e, em outros momentos, com características das

\footnotetext{
${ }^{12}$ Esses autores realizaram uma investigação encomendada pelo Departamento de Estudos e Pesquisas da Biblioteca Pública da Informação (BPI) do Centro Georges Pompidou.
} 
práticas de copiar e colar textos propagados na internet de outra autoria ou do próprio Erico Verissimo. Logo, colocam-se em questão conceitos sobre autoria, produção e criação, problematizando os usos e as produções dos/nos espaços virtuais.

A leitura é uma atitude "intelectual” que permite a "reapropriação", o "desvio", a “desconfiança” ou "resistência”, nas palavras de Chartier (1990, p. 59-60). Dessa forma, o leitor, durante a operação da leitura, é capaz de construir uma pluralidade de significações que não necessariamente correspondem às intenções e ideias do autor, isso porque o leitor, literalmente, “inventa”, cria, recria.

\section{Leitores de Erico Verissimo: reflexões conceituais sobre os modos de ser e estar no mundo}

Em rede de interação e comunicação, escritas, sinais, códigos, símbolos, representações, fotografias são possibilidades de evidenciar histórias, informações, debates e, entre outras produções, reescritas, edições e mixagem de textos escritos, imagéticos ou sonoros. Enfim, definida por diferentes materiais e ferramentas, a escrita eletrônica convive, ao mesmo tempo, com outros suportes de leitura como o manuscrito e o impresso. A cultura escrita, de modo geral, pode ser localizada nos mais diferentes suportes seja nos manuscritos, impressos ou digitais, e este fato, revela novos desafios e novas reflexões sobre os modos de produzir escritas e os modos de ler textos.

Os escritos nos meios digitais superam a ideia de que apenas algumas pessoas são capazes de escrever e publicar. Isso porque as práticas nas redes sociais na internet revelam cada vez mais um público crescente que acessa páginas, produz e veicula informações por textos sejam de sua autoria ou não. Os requisitos básicos para essas operações são, no mínimo: ler; escrever; e utilizar o recurso para divulgação no espaço desejado, numa página de um determinado site, blog ou rede social.

A aventura pela internet destaca um mundo permeado por escritas, imagens e sons. Inúmeras redes de comunicação e interação ligadas em rede mundial, por meio de computadores, celulares, tablets e outros dispositivos são integrados por um conjunto de protocolos de comunicação em uma trama que possibilita a veiculação de informações e a transmissão e troca de dados. A amplitude dos recursos dispostos e dos serviços que 
podem ser utilizados promovem várias ligações ao alcance de uma rede mundial, a World Wide Web, e também o suporte necessário capaz de prestar serviços diversos que envolvem desde a comunicação rápida até o compartilhamento de arquivos.

Textos são criados, inéditos, copiados, compilados, organizados, sofisticados em um emaranhado de ações por meio de cliques que remetem a uma infinita possibilidade de acessos de páginas espalhadas pelo "mar da internet”. A "experiência”, no sentido etimológico da sua palavra, refere-se a significados como: ensaiar algo; verificar as qualidades de algo; pôr à prova, conhecer por experiência; sentir alguma coisa. Essas interpretações ${ }^{13}$ atreladas à experiência dos usuários na internet indicam que os mesmos ensaiam escritas virtuais, copiam e compartilham informações, verificam as características que definem o recurso digital, colocam à prova se esses mesmos recursos são interessantes ou não, conhecem os instrumentos de leitura e escrita digital pela própria vivência em si, e, por fim, produzem inúmeras sensações diante da tela de um computador, notebook, netbook, ultrabook, tablet, celular, entre outras possibilidades digitais.

Desse modo, leitor@s publicaram na internet vários conteúdos como textos, canções, fotos e vídeos. Criaram um conjunto de práticas de comunicação e interação em permanentes mudanças. Neste caso, o tripé da produção, publicação e circulação dos escritos (CHARTIER, 2002a) convivem no mesmo espaço virtual. Fragmentos de informações dispersas e variadas são possíveis de ser consultadas ao longo do dia. Links e referências destacam um texto em comunicação com outros textos, auxiliam os internautas a agregar mais informações sobre o assunto escolhido. Trata-se, portanto, do hipertexto ${ }^{14}$, disposto a partir de uma dinamicidade que disponibiliza um fluxo intenso e

\footnotetext{
${ }^{13}$ Estudiosos franceses como Pierre Lévy (2007), filósofo das tecnologias da inteligência e da cultura virtual contemporânea, e Roger Chartier (1990; 1991; 1994; 1996; 1999; 2002a; 2002b; 2004; 2009), historiador das práticas de leitura, discutem a relação entre os mais tradicionais e os novos suportes de registro e divulgação da escrita. Além deles, pesquisadores norte-americanos como Jay Bolter (2001) e George Landow $(1995 ; 1997)$ destacam o universo das tecnologias e novas mídias realçando a superação das noções como hierarquia, sequencialidade e linearidade do texto, a partir das experiências hipertextuais, isso porque essas potencializam novas construções de sentido sobre a leitura em suportes eletrônicos.

${ }^{14}$ Conforme Landow (1995), hipertexto é um termo cunhado por Theodor Nelson na década de 1970 para se referir ao tipo de texto eletrônico. Traduzido por um recurso tecnológico da área da informática que é reconhecido pelo poder de conectar uma passagem de discurso verbal para imagens, mapas, diagramas e sons, do mesmo modo que consegue se conectar a outros fragmentos verbais. Essa definição amplia a noção que temos acerca do que é um texto porque se trata de uma escrita que não possui uma sequência, mas um texto com várias "bifurcações" em que o leitor é aquele que define o seu roteiro de apreciações
} 
contínuo de conceitos, imagens, juízos, palavras, dados, ideias em um específico modo de escrita. Essa composição demarca a constituição dos limites da esfera do público e privado cada vez mais tênues. Um conjunto de aparelhos possibilita uma série de técnicas de produção, de criação, de editoração aparentemente, ao alcance de todos. São textos com formatos próprios que dialogam com outros textos e assim, viabilizam uma estrutura de criação em grupo, ou provocando a coletividade entre os indíviduos que interveem para alguém tornar-se coautor de um texto.

A disponibilidade de informações dispersas e variadas provoca no usuário a capacidade de comparar, escolher, editar e divulgar o que o mesmo prioriza como importante para compartilhamento. Isso significa que se concentra no usuário a viabilidade de revisar, ilustrar e editar no sentido exato das funções. Fato surpreendente, tendo em vista as gerações anteriores demarcadas por profissionais específicos para cada uma dessas ações. É claro que não se trata de um livro, mas sim de uma edição on-line que revela textos digitais cercados por links, referências ou hipertextos em um movimento ativo complementar. Os usos das diferentes linguagens combinam imagens, sons e palavras, geram práticas de leitura fragmentada e distante da perspectiva linear com que nos deparamos no suporte de um livro impresso.

O hipertexto caracteriza-se por um conjunto sequencial e particular de possíveis ações de leitura e também de escrita, que ocorre de modo não linear e é direcionado a uma infinidade de textos de maneira rápida e instantânea. Deste modo, há uma amplitude de associações em que o usuário pode ser levado a pensar, sentir e agir diante da tela, a partir dos seus movimentos entre um clique e outro que o direciona a vários outros links. A relevância dos textos ganha espaço e destaque no texto eletrônico a um modo de edição hipertextual, no qual o leitor escolhe o que deseja ler e como interagir com textos que são conectados entre si por meio de percursos distintos de localização dos assuntos do seu interesse. Assim, os internautas e leitor@s em análise recolheram vários textos fragmentados e formaram para si uma espécie de mosaico de imagens, palavras, frases, sons, sensações que traduziram informações. Neste caso, refere-se à dispersão de informações por intermédio da comunicação verbal e não verbal.

das páginas de leitura e também de escrita "multilinear" ou "multisequencial". Neste sentido, há uma espécie de jogo com novas regras e experiências que superam os limites de unidade de um texto. 
Com base nos dados explorados, é possível constatar novos modos de escrever e de se comunicar na rede, as mais variadas leituras e, consequentemente, isso também altera o modo como os leitores leem o texto impresso e como lidam com o texto virtual. Este último, sugere vários “caminhos a percorrer”, ou ainda, vários “mares a navegar”. Esses percursos são particulares e por isso, constroem sujeitos que não são apenas usuários da internet, mas que também atuam em redes ao participar de grupos públicos ou privados com assuntos exclusivos.

A interação leitor e texto ${ }^{15}$ configura processos de significados construídos a partir dos próprios textos e dos assuntos ligados ao conteúdo e a hipertextualidade presente. 0 lugar da leitura, seja no papel ou no meio virtual, é mediado por uma série de recursos que estimulam os sentidos para refletir, opinar e atuar nesses espaços. Esse "circuito" admite que existam variações das condições conforme o lugar e a época, mas de modo geral pode ser descrito como um modelo que considera o percurso desde o autor, o editor, o impressor, o distribuidor, o vendedor até chegar às mãos do leitor.

A abordagem adotada compreende a noção de "modos de ler", baseado nos estudos do historiador francês Roger Chartier (1990; 1991; 1994; 1996a; 1996b; 1999; 2002a; 2002b; 2004; 2009a; 2009b). Ao constatar processos de invenção e criação nas redes ${ }^{16}$ escolhidas, via internet, é possível considerar, segundo Lévy (2007), que entre os “atores humanos" as “técnicas” são inventadas, produzidas, utilizadas e interpretadas de diferentes formas. Esses conceitos afirmam que o processo de ler envolve diversos elementos que antecedem a prática efetiva do ato de ler. Remete à constituição da materialidade dos objetos da leitura, dos materiais específicos, do "uso do corpo", da “inscrição em um espaço", da "relação consigo e com o outro" (CHARTIER, 2002a, p. 70).

\footnotetext{
${ }^{15}$ A literatura pode ser analisada como possibilidades educativas a partir das leituras recomendadas na esfera escolar, mas segundo Mathieu Bégin (2011), da Université de Sherbrooke, raro é localizar pesquisas que se dediquem à literatura, especialmente para jovens, como uma prática de divertimento, de socialização e de enriquecimento pessoal. Este trabalho identifica justamente tais dimensões raras em termos de pesquisa. Para Bégin (2011), é surpreendente analisar pelo viés da história das práticas de leitura como esse território foi e é explorado pelos leitores.

${ }^{16}$ Jorge Landow $(1995 ; 2006)$ defende que há uma tendência em convergir o hipertexto e essas teorias, assim como teóricos que compartilham de ideias que poderiam ser postas como modelos conceituais convergentes ao contrapor princípios como linearidade e hierarquia e defender ideias vinculadas às "redes", "links" ou "ligações", "nós", multilinearidade. Nessa perspectiva, os limites entre a relação autor e leitor são tênues, ou seja, permeada por proximidades, e ao mesmo tempo, é possível pensar na relação existente entre a produção de sentido influenciada pelo suporte impresso ao se deparar com a hipertextualidade.
} 
As "práticas de leitura" não são apenas uma "operação abstrata de intelecção", mas compreendem as práticas culturais e suas respectivas reorganizações no meio social (CHARTIER, 2002a, p. 70). Isso porque o ato de ler trata das "significações plurais" e "móveis" localizadas em uma espécie de consonância com os hábitos culturais de um determinado tempo, ou seja, os modos de ler referem-se às práticas inscritas em uma rede social e cultural específica. Considerar essa perspectiva, segundo Chartier (1990), significa pesquisar as modalidades de ler, sejam elas coletivas ou individuais, herdadas ou inovadoras, populares ou letradas, íntimas ou públicas, intensivas ou extensivas, orais ou silenciosas.

A produção de sentido a partir das leituras significa como os leitores compreendem a si próprios e o mundo, por meio da relação estabelecida com o "mundo do texto" (CHARTIER, 1990, p. 24). Portanto, a leitura é entendida como um "ato concreto" que requer leitores dotados de "competências específicas" e caracterizados pela sua prática de ler que constrói sentido, ou seja, a interpretação (CHARTIER, 1990, p. 25).

Isso também pressupõe perceber os modos de ler e o processo pelo qual os leitores dão sentidos aos textos dos quais se apropriam. Essa perspectiva é discutida por Chartier (2002a) como a possibilidade de pensar a "produção da significação", o que implica uma relação dialógica entre as propostas das obras e as categorias estéticas e interpretativas de seus públicos leitores; como também uma interação dinâmica entre texto e leitor; e o resultado de uma negociação entre as obras e os discursos ou as práticas ordinárias.

Através dessa abordagem e aliado ao pensamento de Robert Darnton (1995), é possível considerar a complexidade e as dificuldades em definir e identificar como os leitores assimilam as suas leituras e quais são os efeitos produzidos pelos textos lidos. Para historiadores da leitura, esse campo foi por muito tempo reconhecido como complexo e de difícil acesso, mas, diferentemente dos séculos anteriores ao início do século XXI, em tempos atuais, é possível constatar "rastros", "pistas" e "vestígios" da instância das práticas de leituras que os próprios leitor@s deixam revelar por meio das suas publicações na internet. Essa afirmação pode ser considerada como um fenômeno até então de difícil apreensão na História da Leitura, já que os estudos anteriores de 
Chartier (1990) e Darnton (1995) demonstram as dificuldades de fontes que permitam acesso à esfera dos leitores e suas práticas de ler.

Fundamentado em Vincent Jouve (2008), a noção de leitura e de competência para ler é compreendida como uma atividade multifacetada que envolve processos neurofisiológicos, cognitivos, afetivos, argumentativos e simbólicos. Considerando esses aspectos, a leitura supõe determinadas competências que incluem as esferas individual e cultural. Isso acontece quando o leitor converte palavras em "elementos de significação" (Jouve, 2008), o que promove ações de abstração. Assim, ele dedica a sua atenção para a sequência de eventos descritos no livro que lê ou não o acompanha de maneira linear, o que depende da relação do leitor com o enredo do gênero literário específico. Por isso, a depender do tipo de texto são produzidos determinados tipos de leitura que podem provocar o riso, o fascínio, a indignação, a tristeza, e etc., de tal modo que suscitam os sentidos de múltiplas formas.

Portanto, este trabalho define a interação entre duas dimensões de análise que envolvem os leitores e suas relações com a leitura das obras de EV: (1) a dimensão intelectual-subjetiva da leitura, analisada a partir das respectivas críticas e interpretações da obra que os leitores e leitoras de Erico Verissimo (LEV) fazem sobre o texto lido, ou seja, dos relatos de como percebem a obra; (2) e a dimensão social, revelada na interação entre os pares nos ambientes virtuais em uma perspectiva de escrita baseada na cooperação e colaboração entre eles.

No tocante às escritas dos leitores de EV, essas revelaram elementos presentes nas atividades de leitura como: percepção sobre o que leram, sobre si e o mundo em que vivem, e necessidade de atenção para a prática e a inferência de caráter pessoal, ao comentarem suas apreciações críticas dos romances e memórias de leitura. Os dados coletados e analisados demonstraram que as escritas dos LEV são do livro impresso; eles preferem as páginas do livro quando leem Erico Verissimo, mas se utilizaram das diferentes linguagens da internet para consultar informações e interagir com aqueles que também admiram o escritor em uma dimensão social de interação e colaboração. Embora a leitura dessa comunidade identificada, seja, via de regra, silenciosa e individual, ganha uma nova modalidade quando esses leitores acessam as páginas da internet, pois agregam à leitura o uso e as práticas da cibercultura capazes de ampliar o sentido 
atribuído ao que leram no livro. Isso porque a rede específica analisada recorre às imagens, fotografias, transcrições de trechos lidos, notícias de jornais e revistas, publicação das suas impressões relacionadas ao escritor e à sua obra. Desse modo, eles se utilizaram de várias linguagens ao mesmo tempo, sejam elas imagéticas, sonoras, visuais, informativas, impressas. Ao interagir com os seus pares é como se a leitura que antes era individual e silenciosa, se alterasse para um jogo de trocas e compartilhamentos diante da tela do computador. Assim, a interpretação sobre o que leram no impresso transforma-se em uma dimensão colaborativa e em grupo, quando elaboram enquetes sobre os romances ou personagens favoritos, seja na comunidade do Orkut ou no grupo de discussão via e-mails ou, ainda, quando criam fóruns temáticos para discutir o enredo dos livros.

Os aspectos relacionados às convenções, normas e aos valores atribuídos às leituras de obras do escritor gaúcho são elementos reveladores dos modos de ler, da interação leitor e texto, dos limites e regras para as ações de leitura. Nessa direção,a discussão potencializa o debate acerca da leitura no Brasil com a inserção das práticas digitais.

\section{Considerações finais}

Os leitores e as leitoras de Erico Verissimo, escritores-atores-atuantes, publicaram em blogs, criaram sites, participaram de comunidades e grupos de discussões que compartilharam suas experiências de leitura das obras do seu escritor preferido. Os dados sinalizam práticas sociais e culturais, demonstram modos e espaços de discussão acerca da obra, interagem entre si e mantêm uma conectividade com outras redes sociais. Um dos pressupostos da investigação, portanto, é o de que essas produções indicam modos de ler apropriações de leituras. Além disso, evidenciam que interagem e são, ao mesmo tempo, escritores dos seus próprios textos, na internet.

A problematização demonstra que os leitores e leitoras estão conectados em espaços específicos na internet, em uma interação própria das "redes" sociais que produzem escritores dos seus próprios textos, em alguns momentos, e que, em outros momentos, são divulgadores de informações. São estabelecidas trocas de informações 
por meio das escritas e saberes compartilhados via a conectividade mencionada. Essas questões estão interligadas entre a divulgação da Literatura do escritor EV e, consequentemente, os espaços de difusão da obra a partir de alguns sites. A conceituação teórica dada põe em evidência a relação intrínseca entre a "difusão" e a criação de "redes", conforme Pierre Lévy (2007).

Os leitores em foco compartilharam experiências e narraram percursos singulares de conhecimento da literatura dentro e fora da escola: ao relatarem como conheceram o escritor, identificaram as obras e as suas personagens favoritas. Desse modo, os dados analisados evidenciam que os livros provocaram o envolvimento sensível com o estilo literário do escritor e isso motivou a leitura gradativa de outras obras. Tais livros foram lidos e relidos pela comunidade de leitores em análise; isso significa admitir que a leitura pode envolver emoções que suscitam um “processo afetivo”, já que o leitor aciona as capacidades reflexivas em uma espécie de “jogo textual” (JOUVE, 2010).

Portanto, os resultados desta análise sinalizam que o sentimento de pertencimento a um grupo indica haver uma mútua cooperação a partir das ações dos leitores em sugerir propostas coletivas, dialogar, tomar decisões, comentar nos fóruns, emails e mensagens. Por essa razão, a partir do momento em que se identificam como um "grupo de admiradores" de Erico Verissimo, os participantes desta comunidade constroem modos de ser e estar no mundo, e assim, transmitem suas convicções e perspectivas por intermédio dos seus percursos educacionais. Com isso, indicam o redimensionamento da leitura ao afirmar que a leitura do impresso não está dissociada de outras linguagens, pois existe a potencialidade de várias conexões e interligações com assuntos afins.

O fascínio por ler, o deleite em contato com a materialidade do livro impresso, a percepção sobre o mundo e as ligações entre ficção e realidade estão presentes nas escritas dos leitor@s. A leitura parece proporcionar ao leitor o contato consigo, com a sua intimidade, com as formas de enxergar a si e ao mundo, uma vez que ele é capaz de atribuir significado à leitura ficcional estabelecendo uma associação com a sua vida e suas experiências e percepções sobre o conteúdo lido.

Eles são leitor@s do livro impresso e leitores-escritores na internet, produzem práticas memorialísticas na cibercultura e apontam modos de ler o impresso e modos de 
escrever na internet. É inegável constatar que as inovações tecnológicas promovem atualizações sobre a realidade e "invadem" os espaços de relações sociais modificando os seus hábitos, mas são as apropriações, os usos, os costumes, as tradições, as necessidades, as práticas, os significados atribuídos socialmente que definem o modo como a tecnologia é empregada, e, neste trabalho, é demonstrado em um grupo de leitor@s de Erico Verissimo que escreve na internet.

\section{Referências}

AGUITON, Christophe; CARDON, Dominique. Expression de soi et creations identitaires sur le web 2.0. In: Lecture jeune. Mars 2010. $33^{\mathrm{a}}$ année. [p.4-9].

ASSMANN, Hugo. A metamorfose do aprender na sociedade do conhecimento. In: ASSMANN, Hugo (Org.). Redes digitais e metamorfose do aprender. Petrópolis: Editora Vozes, 2005.

AURAY, Nicolas. Les jeunes et la culture numérique: des audiences actives aux parcours créatifs. In: Lecture jeune. Mars 2010. $33^{\mathrm{a}}$ année. [p. 16-20].

BÉGIN, Mathieu. Le forum de discussion sur Internet comme lieu d'étude de la réception des productions littéraires jeunesse: le cas de la série Pavel 1. Communication, Lettres Et Sciences du Langage, v. 5, n. 1. ago., 2011.

BOLTER, Jay David Bolter. Writing space: computers. New Jersey: Lawrence ErlBaum Associates Publishers, 2001.

BUTLEN, Max. Les politiques de lecture et leurs acteurs, 1980-2000. Lyon: INRP, 2008.

CASTELLS, Manuel. A Sociedade em rede: do conhecimento à política. In: CASTELLS, Manuel; CARDOSO, Gustavo (Orgs.). A Sociedade em rede do conhecimento à acção política. Brasilia: Imprensa Nacional - Casa da Moeda. 2005. Disponível em: <http://www.cies.iscte.pt/destaques/documents/Sociedade_em_Rede_CC.pdf >. Acesso em: 03 out. 2013. 
CAVALLO, Guglielmo; CHARTIER, Roger (Coords.). Histoire de la lecture dans le monde occidental. Paris: Éditions Seuil, 1997.

CERTEAU, Michel de. A invenção do cotidiano. v. 1.: artes de fazer. Petrópolis: Vozes, 1994.

CHARTIER, Anne-Marie; HÉBRAD, Jean. Discours sur la lecture (1880-2000). Paris: BPI Centre Georges Pompidou, Fayard (Nouvelles études historiques), 2000.

CHARTIER, Roger. À beira da falésia: a história entre incertezas e quietudes. Porto Alegre: Editora da UFRGS, $2002 \mathrm{a}$.

CHARTIER, Roger. A história cultural: entre práticas e representações. Rio de Janeiro: Bertrand Brasil, 1990.

CHARTIER, Roger. A leitura: uma prática cultural: debate entre Pierre Bourdieu e CHARTIER, Roger. In: CHARTIER, Roger (Org.). Práticas de leitura. São Paulo: Estação Liberdade, $1996 \mathrm{~b}$.

CHARTIER, Roger. A ordem dos livros: leitores, autores e bibliotecas na Europa entre os séculos XIV e XVIII. Brasília: UNB, 1994.

CHARTIER, Roger. As revoluções da leitura no ocidente. In: ABREU, Márcia (Org.). Leitura, história e história da leitura. Campinas, SP: Mercado das Letras; ALB; FAPESP, 1999.

CHARTIER, Roger. Do livro à leitura. In: CHARTIER, Roger (Org.). Práticas de leitura. São Paulo: Estação Liberdade, 1996a.

CHARTIER, Roger. Leituras e leitores na França do antigo regime. São Paulo: Editora UNESP, 2004.

CHARTIER, Roger. O mundo como representação. Estudos Avançados, São Paulo: Instituto Avançado, USP, v. 5 n. 11, jan./abr., 1991.

CHARTIER, Roger. À beira da falésia: a história entre incertezas e quietudes. Porto Alegre: Editora da UFRGS, 2002a.

CHARTIER, Roger. Os desafios da escrita. São Paulo: Editora UNESP, 2002b.

DARNTON, Robert. O beijo de Lamourette: mídia, cultura e revolução. São Paulo: Cia. das Letras, 1995.

DARNTON, Robert. A questão dos livros: presente, passado e futuro. São Paulo: Companhia das Letras, 2010.

JOUVE, Vincent. La Lecture. Paris: Hachette Collection - Contours Littéraires, 2008. 
JOUVE, Vincent. Pourquoi étudier la littérature? Paris: Armand Colin, 2010.

LANDOW, George. Hipertexto: La convergencia de la teoría crítica contemporánea y la tecnología. 1. ed. Barcelona: Paidos, 1995. Hipermedia, 2.

LANDOW, George. Teorías del hipertexto. Madrid: Paidos, 1997.

LÉVY, Pierre. Cibercultura. São Paulo: Ed. 34, 2007. (Coleção Trans).

LÉVY, Pierre. O que é virtual? Rio de Janeiro: Editora 34, 1996.

MORAIS, Roselusia Teresa Pereira de. Modos de ler o impresso, modos de escrever na internet: escritas de leitores e leitoras do escritor Erico Verissimo. 2014. $221 \mathrm{f}$. Tese (Doutorado em Educação) - Programa de Pós-Graduação em Educação, Faculdade de Educação, Universidade Federal de Pelotas, Pelotas, 2014.

OCTOBRE, Sylvie. Nouvelles cultures et institutions de transmission. Lecture jeune, 33. année, p. 4-9. mars. 2010.

REGIS, Sônia. Modos de ler, modos de pensar: leitura e memória. In: ABREU, Márcia; SCHAPOCHNIK, Nelson (Orgs.). Cultura letrada no Brasil: objetos e práticas. Campinas, SP: Mercado de Letras, Associação de Leitura no Brasil (ALB). São Paulo, SP: Fapesp, 2005. (Coleção Histórias de Leitura), p. 511-518.

SÉVERAC, Pascal (Coord.). Lire et ecrire. Paris: Éditions Sciences Humaines, 2007. VERISSIMO, Erico. Solo de Clarineta I. $15^{\circ}$ ed. Porto Alegre: Editora Globo. $1981 \mathrm{~d} .1^{\circ}$ vol.

Universidade do Estado de Santa Catarina - UDESC

Programa de Pós-Graduação em Educação - PPGE

Revista Linhas

Volume 19 - Número 41 - Ano 2018 revistalinhas@gmail.com 